


\title{
Direitos laborais e desenvolvimento: interconexões
}

\section{Autor(es): $\quad$ Cecato, Maria Aurea Baroni}

Publicado por: Faculdade de Direito da Universidade de Coimbra

URL persistente:

URI:http://hdl.handle.net/10316.2/24750

DOI:

http://dx.doi.org/10.14195/0870-4260_51_6

Accessed : $\quad$ 26-Apr-2023 14:55:56

A navegação consulta e descarregamento dos títulos inseridos nas Bibliotecas Digitais UC Digitalis, UC Pombalina e UC Impactum, pressupõem a aceitação plena e sem reservas dos Termos e Condições de Uso destas Bibliotecas Digitais, disponíveis em https://digitalis.uc.pt/pt-pt/termos.

Conforme exposto nos referidos Termos e Condições de Uso, o descarregamento de títulos de acesso restrito requer uma licença válida de autorização devendo o utilizador aceder ao(s) documento(s) a partir de um endereço de IP da instituição detentora da supramencionada licença.

Ao utilizador é apenas permitido o descarregamento para uso pessoal, pelo que o emprego do(s) título(s) descarregado(s) para outro fim, designadamente comercial, carece de autorização do respetivo autor ou editor da obra.

Na medida em que todas as obras da UC Digitalis se encontram protegidas pelo Código do Direito de Autor e Direitos Conexos e demais legislação aplicável, toda a cópia, parcial ou total, deste documento, nos casos em que é legalmente admitida, deverá conter ou fazer-se acompanhar por este aviso.

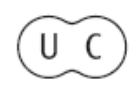




\section{UNIVERSIDADE DE COIMBRA \\ FACULDADE DE DIREITO}

BOLETIII DE CÊACCLS ECONÓNCACAS

VOLUME LI

$\begin{array}{llll}2 & 0 & 0 & 8\end{array}$



COIMBRA 


\section{DIREITOS LABORAIS \\ E DESENVOLVIMENTO: INTERCONEXÕES}

"Privatizaram sua vida, seu trabalho, sua hora de amar e seu direito de pensar. É da empresa privada o seu passo em frente, seu pão e seu salário." (Bertold Brecht, 1898-1956)

\section{Para introduzir}

As conexões que se estabelecem entre direitos laborais e desenvolvimento passam, antes de tudo, pelos direitos econômicos e sociais, os quais, por sua vez, se firmam sobre os direitos civis e políticos e têm sua efetivação também assentada nos direitos de solidariedade e fraternidade. Estabelecem-se, portanto, no princípio da indivisibilidade dos direitos humanos e fundamentais, indivisibilidade essa apreendida na realidade e afirmada a partir da Declaração Universal dos Direitos Humanos (ONU, 1948), marco contemporâneo da sustentação da dignidade do ser humano.

Os problemas relativos ao exercício dos direitos econômicos - dos quais não se apartam os sociais, e, portanto, também não os laborais - vêm sendo inseridos no contexto da intensificação da globalização econômica das últimas décadas. Aqueles problemas não têm origem na globalização. Mas têm nela a fonte de grande parte de sua própria intensificação. 
Com efeito, a globalização provoca a crise dos tradicionais modelos políticos e convulsiona a estrutura dos compromissos sociais. No crescimento da interdependência da economia mundial e igual expansão do poderio privado, o Estado vem perdendo o papel que lhe cabia no status anterior, de regular as relações sociais e de definir as obrigações destas resultantes. $\mathrm{Na}$ fluidez das fronteiras físicas e na nova dinâmica das trocas e investimentos, o encolhimento do Estado tradicional gera espaço para o que seria um novo modelo, mas que não o é por falta de consenso na definição dos paradigmas necessários.

A complexidade do domínio da questão é problema de todos, mas, indubitavelmente, atinge mais fortemente aqueles que sempre foram excluídos da informação, por falta da formação necessária e das oportunidades que levariam ao alcance dessa complexidade. Nesse contexto se acha o trabalhador, particularmente nos países em que a curta dimensão do desenvolvimento o conservou à margem da sociedade. Quero dizer com isso, à margem do consumo, das condições de bem-estar em geral, das decisões que lhe dizem respeito e mesmo da produção, no caso dos desempregados.

Por outro lado, os sindicatos, seus representantes nas relações com os órgãos de decisão, públicos ou privados, perdem o relativo controle de que dispunham sobre a situação que lhes é diretamente atinente.

As vantagens da globalização - e ela, evidentemente, as tem - são alcançadas pelas minorias, sem partilha, o que aumenta o fosso anteriormente existente entre os mais favorecidos pelo mercado e os alijados dos contornos deste.

Com efeito, o processo da globalização econômica, especialmente no que diz respeito à produção, ao comércio e aos investimentos, atinge forte e duramente os direitos laborais. O trabalho subserviente, terceirizado, informal e de escassas condições de dignidade, em geral, assim como a 
exclusão do acesso à terra e ao emprego deixam o trabalhador cada vez mais à margem das regras da economia de mercado. O Estado, instado a se ausentar das relações capital-trabalho, enfrenta obstáculos na concorrência com outros atores do mundo das decisões e regulamentações. Aliás, poder-se-ia dizer, da desregulamentação.

Entretanto, é nesse mesmo contexto que crescem, em quantidade e qualidade, os movimentos sociais de reivindicação de direitos que promovam e garantam a dignidade do trabalhador. De resto, a história ensina que é nos processos de maior aviltamento das condições de trabalho que as reações desses movimentos se acentuam.

Dessa feita, em paralelo com as pressões no sentido da flexibilização das normas laborais e da redução de garantias de bem-estar dos trabalhadores, em favor dos interesses econômicos, crescem as demandas pela inclusão sócio-laboral e pelo exercício do direito ao desenvolvimento. Em grande parte, as reivindicações dos movimentos sociais estão na base das agendas de atuação das Organizações Internacionais que têm por objetivo a universalização dos direitos fundamentais, e influenciam também os documentos jurídicos discutidos e aprovados nos âmbitos destas.

\section{Conexão entre direitos laborais e direito ao desenvolvimento}

Ao longo da história, a produção de bens para suprimento de necessidades sempre foi preocupação do ser humano, pela premência advinda das necessidades básicas. Igual preocupação é gerada pela idéia do conforto que advém da produção, que permite acúmulo de bens e riquezas.

$\mathrm{O}$ capitalismo tem relevância nesse contexto. $\mathrm{O}$ afã humano de produzir para enriquecer, embasado no indi- 
vidualismo e na concorrência, na aposta no mercado e na retração do Estado. Prima pelo crescimento econômico e acumula bens pela tranqüilidade que proporcionam as reservas, mas também com o objetivo do reinvestimento permanente. Recebe forte impulso das revoluções burguesas e industriais do século XVIII e enfrenta, é verdade, as investidas dos ideais socialistas. Curva-se diante de algumas das reivindicações dos movimentos sociais e, sobretudo, dos trabalhadores organizados, admitindo a instituição dos direitos sociais. Reanima-se com a queda do socialismo real e ganha novo e último impulso com a acentuação da mundialização econômica. O crescimento econômico buscado e alcançado é, sem sombra de dúvidas, um ganho para a $\mathrm{Hu}-$ manidade: garante o bem-estar material e, ao mesmo tempo, é base para a criação de oportunidades que levam à consecução dos imateriais.

Entretanto, do outro lado da dinâmica do capitalismo e da geração de riquezas, encontra-se um cenário onde a pobreza é fenômeno mundial, de múltiplas dimensões, repercussões e fontes. Uma dessas fontes tem, indubitavelmente, forte conexão com a ausência de trabalho e emprego, assim como com a precariedade das condições em que o trabalho se realiza, que vão desde o confinamento do trabalhador e outros tratamentos desumanos, até a terceirização, a informalidade e, portanto, a carência total de regulação; as jornadas exaustivas; as enfermidades e a debilidade da remuneração.

Mas é fato que as Declarações de direitos, surgidas a partir dos meados do século passado, denotam a preocupação das organizações internacionais com os direitos e garantias de participação efetiva do ser humano na sociedade, onde o trabalhador é, necessariamente, parte relevante. E é, de resto, parte numericamente considerável, representando a maioria da população do planeta em idade e condições de produzir, visto que aqui o trabalhador deve ser entendido 
não só como aquele que trabalha, mas também como aquele que não o faz por não ter acesso ao trabalho ou ao emprego.

No sentido do que acima se diz, estão edificados os preceitos da Declaração Universal dos Direitos Humanos DUDH (ONU, 1948) - consagrados direta ou indiretamente à seara do trabalho. Indiretamente, em sua integralidade, referente aos direitos essenciais e necessidades de todo ser humano, no que é mais voltada para as liberdades - direitos civis e políticos, por um lado e, por outro, para os direitos econômicos e sociais. E diretamente, em seus artigos XXIII, XXIV e XXV, que estabelecem direitos como: emprego com livre escolha; condições justas e favoráveis de trabalho; remuneração justa e satisfatória; organização sindical livre; proteção contra o desemprego; segurança social, assim como limitação da jornada para o repouso e o lazer ${ }^{1}$.

É também da ONU a Declaração de 1986, sobre o direito ao desenvolvimento. O documento, trazendo nova acepção formal ao termo desenvolvimento, constitui claro suporte dos direitos fundamentais dos trabalhadores.

Preceito síntese da mencionada Declaração é o que especifica que, para que o desenvolvimento se concretize, devem ser concedidas oportunidades de participação no processo produtivo e nos benefícios dos resultados deste. Com efeito, o artigo $1^{\circ}$ do documento em tela determina que "o direito ao desenvolvimento é um direito inalienável do homem, em virtude do qual toda pessoa humana e todos os povos têm o direito de participar e de contribuir para um desenvolvimento econômico, social, cultural e político, no qual todos os direitos do homem e todas as liberdades

1 Não se pode olvidar a relevância do Pacto Internacional de Direitos Civis e Políticos, assim como do Pacto Internacional de Direitos Econômicos, Sociais e Culturais - ONU, 1966. 
fundamentais possam ser plenamente realizados, e de usufruir desse desenvolvimento" 2 .

Dessa feita, no que concerne ao mundo do trabalho, parece simples a inferência de que inalienável é, antes de tudo, o direito de trabalhar e, portanto, o acesso ao trabalho, sem o qual, evidentemente, não há que se falar em participação ativa do trabalhador na produção. Por outro lado, é imperioso considerar que o termo produção tem, no texto, semântica mais ampla do que aquela que lhe é atribuída ordinariamente: não se reporta apenas a bens materiais, mas a todos aqueles que, em conjunto, formam os elementos necessários ao chamado bem-estar.

Assim, o trabalho realizado em condições de dignidade é meio de provimento de necessidades materiais, morais e emocionais do trabalhador, aí incluídas a auto-estima e a inserção deste na comunidade em que vive. Para além disso, o trabalho é capaz de minorar a vulnerabilidade do trabalhador à violência e à exploração de toda sorte.

Igualmente inalienável é o direito do trabalhador a beneficiar dos resultados de todo o processo produtivo, o que supõe auferir remuneração que permita o acesso ao consumo. Oportuna é a evocação de que grande parte dos trabalhadores, à escala mundial, e, em particular, nos países de forte concentração de rendas - como é o caso do Brasil - não conta com acesso ao consumo, ao menos não de forma equiparável à energia que despende participando da produção. ${ }^{3}$

${ }^{2}$ No original (francês): "Article Premier. 1. Le droit au développement est un droit inaliénable de l'homme en vertu duquel toute personne humaine et tous les peuples ont le droit de participer et de contribuer à un développement économique, social, culturel et politique dans lequel tous les droits de l'homme et toutes les libertés fondamentales puissent être pleinement réalisés, et de bénéficier de ce développement.

${ }^{3}$ Segundo informação da OIT, quase metade dos trabalhadores do mundo não consegue ganhar o suficiente para ultrapassar, com suas famílias, 
Mas o preceituado pela Declaração de 1986 e, de resto, reafirmado pela Declaração e Programa de Ação de Viena (ONU, 1993) ${ }^{4}$ vai além da simples inferência do que se acaba de observar. São também direitos inalienáveis do trabalhador os que se referem à sua participação nos processos políticos e culturais, assim como o exercício de suas liberdades fundamentais. Nesse sentido, o trabalhador deve ter garantia de tratamento que não atente contra seus direitos civis e políticos (direito à vida e à integridade fisica; liberdade de expressão e de ir e vir, etc.), tanto da parte dos poderes públicos como do lado do empregador (ou de prepostos deste) e deve, ainda, ser sujeito ativo das discussões e decisões que definem seu presente e o que lhe está reservado para o futuro, onde, aliás, seus objetivos e valores devem ser considerados. É, portanto, do efetivo exercício do conjunto desses direitos que se pode esperar o desenvolvimento pleno do trabalhador.

Deve-se considerar, ainda, que o teor da Declaração leva à clara inferência de que o desenvolvimento se coloca para além do crescimento econômico. Com efeito, o texto do documento em análise preceitua a "igualdade de oportunidades de todos no acesso aos recursos básicos, à educação, aos serviços de saúde, à alimentação, à habitação, ao emprego e à repartição eqüânime da renda"'5. Quer dizer: o

a linha de pobreza, recebendo não mais que dois dólares diários. A OIT atribui o fato, em grande parte, ao "sistema globalizado que se apresenta discriminatório e injusto." Informação disponível em: http:// www.ilo.org/global/About_the_ILO/Mainpillars/Workingoutofpoverty/ lang_fr/index.htm. Acesso em: 16 de abril de 2008.

4 Não se pode olvidar a relevância do Pacto Internacional de Direitos Civis e Políticos, assim como do Pacto Internacional de Direitos Econômicos, Sociais e Culturais - ONU, 1966.

${ }^{5}$ No original (francês): “Article 8. 1. Les États doivent prendre, sur le plan national, toutes les mesures nécessaires pour la réalisation du droit 
desenvolvimento supõe também a partilha de oportunidades. Nesse norte, a inclusão social deve prevalecer sobre a acumulação de bens. Não pode falar-se em desenvolvimento sem ter em conta as condições de vida e de trabalho dos trabalhadores, assim como não há como justificar a exclusão sócio-laboral em nome do progresso econômico, devendo este ser entendido como suporte do bem-estar de todos.

A garantia, para o trabalhador, da sua condição de sujeito central do desenvolvimento exige providências. Conforme a Declaração de 1986, cabe aos Estados, fundamentalmente, a tarefa de suplantar os fatores que se colocam como óbices. Assim, e antes de tudo, o direito em tela deve ser recepcionado nos ordenamentos internos, como "pretensão moral justificada", conforme reflexão de PECES$-\mathrm{BARBA}^{6}$, referindo-se aos direitos fundamentais em geral. Por óbvio, a real efetivação do direito ao desenvolvimento não prescinde de políticas e ações públicas.

Por outro lado, a Declaração de 1986 apela à cooperação internacional, evocando os compromissos assumidos pelos Estados na Carta Constitucional da ONU e em todos os Tratados e Convenções ratificados e Declarações firmadas, que têm como objeto os direitos fundamentais.

\section{Sobre a relação OIT e desenvolvimento}

O fórum internacional das discussões e negociações que se relacionam com o mundo do trabalho é a Organização

\footnotetext{
au développement et ils assurent notamment l'égalité des chances de tous dans l'accès aux ressources de base, à l'éducation, aux services de santé, à l'alimentation, au logement, à l'emploi et à une répartition équitable du revenu."

${ }^{6}$ Peces-Barba Martinez, Gregório, Lecciones de derechos fundamentales, Madrid: Dykisons, 2004, 29.
} 
Internacional do Trabalho (OIT), criada com o propósito de promover a paz mundial, o que, no contexto de 1919, significa atender parte das demandas da organização sindical internacional, influenciada pelas ideologias socialistas. A principal razão da criação da Organização é, dessa feita, a constatação de que a estabilidade do capitalismo não prescinde do controle de revoluções iminentes. As ações e a produção normativa da OIT são, entretanto, desde seu início, igualmente voltadas para a justiça social.

Destaca-se, na produção da OIT, a Declaração de 1998 sobre os princípios e direitos fundamentais no trabalho, marco de uma etapa que tem início na expansão das adesões de Estados membros e no amadurecimento das decisões e ações às quais a Organização imprime valor ético.

O teor da Declaração de 1998 é visivelmente limitado, porquanto fixado no conteúdo de oito Convenções aprovadas durante os longos anos de atuação da OIT: a eliminação do trabalho forçado (Convenções n. ${ }^{\circ} 29$ de 1930 e 105 de 1957) ${ }^{7}$; a erradicação do trabalho infantil (Convenções n. ${ }^{\text {os }} 138$ de 1973 e 182 de 2001) ${ }^{8}$; a não discriminação no trabalho e no emprego (Convenções n. ${ }^{\text {os }} 100$ de 1951 e 111 de 1958) ${ }^{9}$ e a liberdade sindical (Convenções n. ${ }^{\text {os }} 87$ e 98$)^{10}$. O texto aborda quatro aspectos dos direitos fundamentais laborais

${ }^{7}$ Determinam a eliminação do trabalho resultante de coerção; de punição por greve ou por opiniões políticas e ideológicas; imposto como medida discriminatória racial, social, nacional ou religiosa ou com o fim de educação política.

${ }^{8}$ Definem a idade mínima para o trabalho e estabelecem a extinção das piores formas de trabalho de crianças e adolescentes até dezoito anos.

${ }^{9}$ Consideram a discriminação no trabalho e no emprego como toda distinção, exclusão ou preferência fundada em raça, gênero, cor, religião, opinião política, nacionalidade e origem social.

${ }^{10}$ Estabelecem como direitos dos trabalhadores e empregadores: a criação das organizações que lhes pareçam convenientes para defesa de 
que, sozinhos, estão longe de alcançar o resguardo da decência na seara do trabalho.

Para confirmar o que se alega, basta evocar a ausência da busca do pleno emprego (questão que está direta e fortemente relacionada com a pobreza de grande parte dos trabalhadores à escala mundial); a omissão de referência a salários justos e à segurança que trazem os direitos previdenciários e à formação profissional (esta em um momento em que a automatização da produção exige, cada vez mais, conhecimentos e habilidades, alijando grande parte dos trabalhadores do acesso ao emprego). Entretanto, a Declaração tem um valor intrínseco, independente de qualquer crítica: através dela, governos, empregadores e trabalhadores reafirmam a universalidade de princípios e de direitos fundamentais laborais.

De resto, o Preâmbulo da Declaração é relevante na compreensão do texto como um todo. Dele se pode inferir, tanto a pretensão da OIT de ir além do preceituado, como o entendimento da Organização sobre o enfeixamento dos direitos laborais no direito ao desenvolvimento. Na verdade, no Preâmbulo proclama-se que a OIT deve "mobilizar o conjunto de seus meios de ação normativa, de cooperação técnica e de investigação em todos os domínios de sua competência, em particular o emprego, a formação profissional e as condições de trabalho, de forma que, no âmbito de uma estratégia global de desenvolvimento econômico e social, as políticas econômicas e sociais se reforcem mutua-

seus direitos, sem autorização prévia; a decisão sobre a afiliação a tais organizações; a constituição de Federações e Confederações e a afiliação a Organizações Internacionais; a livre administração dos sindicatos, a decisão sobre o estabelecimento de suas ações e programas, sem interferência ou intervenção das autoridades públicas, além da negociação coletiva como fonte de suas condições de trabalho. 
mente, com o objetivo de instaurar um desenvolvimento amplo e sustentável". ${ }^{11}$

É correto salientar, porém, que, na perspectiva e esperança de alcançar condições de dignidade para os trabalhadores, a OIT tem hoje definida uma agenda para a promoção do trabalho decente, para cuja implementação conta com a cooperação da $\mathrm{ONU}^{12}$. A noção de trabalho decente inclui os preceitos da Declaração de 1998, mas projeta-se para além deles, firmando-se sobre quatro pilares: os direitos do trabalhador; o emprego; a proteção social e o diálogo social, com vista à negociação em todos os níveis.

A referida noção vem sendo construída sobre indicadores das necessidades observadas em investigações da própria OIT e dos demais estudiosos da questão. Entretanto, ela já concorre para a orientação necessária à atuação da Organização, a nível mundial, nos diversos setores em que se desdobram os quatro pilares mencionados, para implementação

${ }^{11}$ No original (francês): “Attendu que l'OIT se doit donc plus que jamais de mobiliser l'ensemble de ses moyens d'action normative, de coopération technique et de recherche dans tous les domaines de sa compétence, en particulier l'emploi, la formation professionnelle et les conditions de travail, pour faire en sorte que, dans le cadre d'une stratégie globale de développement économique et social, les politiques économiques et sociales se renforcent mutuellement en vue d'instaurer un développement large et durable;"

${ }^{12}$ A implementação da Agenda e das ações que compõem o seu seguimento se fazem em forte interseção com a Declaração do Milênio da ONU, adotada em 2000. Com efeito, a globalização justa, defendida pela mencionada Declaração, converge com os objetivos delineados para a Agenda da OIT, particularmente no que se refere à redução da pobreza em todo o mundo. Pontos de conexão e atuação conjunta entre a Agenda para o trabalho decente da OIT e a Declaração do Milênio da ONU podem ser verificados no site oficial da OIT: http://www.ilo.org/ public/french/bureau/exrel/mdg/briefs/overview.pdf. 
da decência e honradez nas condições laborais e a promoção do emprego. Observe-se, por fim, que o entrelaçamento dos pilares do trabalho decente permite que os êxitos alcançados em cada um deles repercuta na consecução dos demais, de forma que, se forem levadas a cabo as políticas e ações adequadas, sobrevenha uma realimentação mútua e contínua dos fatores que levam ao pleno emprego e às corretas condições de trabalho.

Entretanto, aqui se poderia questionar a razão pela qual a OIT não aprovou, no texto de 1998, preceituário mais abrangente, mais consentâneo com a realidade atual do mundo do trabalho, assim como com o Preâmbulo da própria Declaração. A questão se coloca no âmbito das negociações que envolvem a diversidade de interesses dos Estados-membros ${ }^{13}$, além de se repercutir para a seara de outras Organizações (como se verá a seguir). Nestas, os Estados-membros são, aproximadamente, os mesmos, mas o fórum de discussão e os fins se distanciam do compromisso com a efetividade dos direitos fundamentais.

\section{Sobre cooperação internacional e desenvolvimento}

As organizações internacionais têm relevante papel na interdependência mundial. A busca por políticas que, nesse contexto, sejam mais coerentes com propósitos de um equilíbrio mundial passa, necessariamente, por um processo de cooperação negociada. Ocorre, entretanto, que as

${ }^{13}$ Em geral há dificuldades para negociar direitos que têm caráter mais fortemente econômico. O que se afirma é confirmado pela constatação de que os direitos considerados fundamentais pela Declaração não oneram as empresas e/ou não são mais admissíveis em qualquer sociedade que se quer democrática. 
referidas organizações podem ter objetivos conflitantes, conquanto seus Estados-membros sejam aproximadamente os mesmos.

Nesse contexto, uma das questões que vêm sendo debatidas pela comunidade internacional é o suposto conflito entre as ações da Organização Mundial do Comércio (OMC) e a promoção dos direitos fundamentais. A existência desse conflito é, de resto, relatada pela Sub-Comissão de promoção e proteção dos direitos do homem, da ONU ${ }^{14}$. As críticas à OMC se fazem, em geral, no sentido de que a Organização deveria cooperar - e não o faz - com as demais Organizações que têm objetivos de fazer cumprir direitos sociais e, mais especificamente, o direito ao desenvolvimento, como é o caso da própria ONU e, em especial, da OIT, que aqui nos interessa em particular. Ainda se faz referência ao fato de que a OMC negligencia seus próprios preceitos mais amplos e fundamentais, em matéria de desenvolvimento sustentável e de crescimento equânime.

Evidentemente, a OMC foi criada no espírito da Conferência de Breton Woods, e, mais precisamente, sobre as bases do Acordo Geral de Tarifas e Comércio (GATT). Tem, como o Banco Mundial (BM), o Fundo Monetário

${ }^{14}$ Consulte-se, a esse propósito: 1. Communiqué de presse DH/G/ $/ 1403$ de La Sous-Commission Des Droits de l'homme - Clôt les travaux de sa cinquante-troisième session, Disponível em: http://www.un.org/News/ fr-press/docs /2001/DHG 1403.doc.htm; 2. O texto de LAMY, Pascal, Les droits économiques, sociaux et culturels dans le contexte des activités de développement des organisations internationales, disponível em : http:// trade.ec.europa.eu/doclib/docs/2004/october/tradoc_119412.pdf; 3. Résolution de la Commission des droits de l'homme 2005/17 du HAUT-COMMISSARIAT DES NATIONS UNIES AUX DROITS DE L'HOMME: La mondialisation et ses effets sur la pleine jouissance des droits de l'homme, disponível em: http://ap.ohchr.org/documents/F/ CHR/resolutions/E-CN_4-RES-2005-17.doc. 
Internacional (FMI) e a Organização de Cooperação e Desenvolvimento Econômico (OCDE), objetivos econômicos e comerciais e vem conseguindo importante expansão mundial desses setores, apesar das práticas hegemónicas por parte dos países de maior crescimento econômico.

Parece claro que a OMC, pela natureza das questões que regula, tem em mãos mecanismos de constrangimento para o cumprimento de suas próprias normas, assim como de outras que se inserem na esfera das produções normativas da ONU e da OIT. A esse respeito, o mundo das relações internacionais governamentais, nos anos noventa, pode observar as instâncias da OIT junto à OMC com vista à obtenção de apoio desta última para o estabelecimento de um vínculo direto entre o comércio e os direitos fundamentais dos trabalhadores.

A proposta de implantação da "cláusula social", como instrumento de sanção comercial pela violação das normas fundamentais laborais, não obteve, entretanto, a cooperação desejada. A OMC, embora reconhecendo a legitimidade das preocupações, argumentou com o risco do surgimento de um neo-protecionismo insidioso.

De fato, a complexa relação entre política social e política comercial gera conflitos entre os países industrializados e os que ainda não alcançaram esse estágio. Os primeiros, em tese, já adotam medidas de proteção mais avançadas e alegam que são, portanto, prejudicados na concorrência comercial. Os últimos, por sua vez, argumentam que a preocupação dos primeiros não é humanitária, mas puramente comercial. Argumentam ainda que já se encontram em posição de desvantagem e, com a adoção da cláusula social, passariam a ter ônus maior no custo de seus produtos, o que redundaria em prejuízo ainda maior na competição internacional.

Assim, conquanto se deva insistir em uma postura ética, diante da questão, o que levaria a considerar que a OMC 
deveria se prestar a apoiar a cláusula social ${ }^{15}$, parece que se deve convir com a improbabilidade de resultados satisfatórios a curto prazo. Entretanto, parece, também, que não se deve perder de vista a discussão. Com efeito, seja através da cláusula social, seja de outros mecanismos a utilizar conjunta ou alternativamente, o papel da OMC é de grande relevância quando se almeja levar todos os Estados - inclusive os não industrializados - ao compromisso de efetivo cumprimento dos direitos laborais fundamentais.

\section{Para finalizar...}

É patente que o crescimento econômico pode contribuir para o exercício dos direitos do homem e criar oportunidades para a realização pessoal, o que, entretanto, não se faz automaticamente. Com efeito, a idéia - sustentada no "Consenso de Washington" e mesmo tradicionalmente argüida - de que o crescimento econômico beneficiaria as camadas menos favorecidas já é suplantada pelo entendimento de que as disparidades sociais não são resolvidas pela ortodoxia do individualismo e da concorrência: as teorias liberais falharam ao prescrever a resolução das desigualdades pelo mercado.

Do quadro aqui exposto pode-se concluir que a complexidade e as disparidades do contexto atual (social e, particularmente, laboral) geram a carência de um consenso definido em regras universais e democráticas, em que as atividades comerciais estejam em coadjuvação com o direito ao desenvolvimento.

${ }^{15}$ De resto, não parece haver, da parte da OIT, renúncia ao pleito, mas tão somente a busca de caminhos alternativos, ao mesmo tempo em que amadurece a reflexão. Esse amadurecimento da reflexão, aliás, não é tarefa só da OIT, mas de toda a comunidade internacional. 
Por outro lado, é na perspectiva da dignidade dos trabalhadores que a OIT busca a promoção universal do trabalho decente, estabelecendo uma agenda que contempla os preceitos da Declaração de 1998 sobre princípios e direitos fundamentais no trabalho, mas indo além, para alcançar os direitos dos trabalhadores: o emprego; a proteção social e o diálogo social. Dentro da preocupação com padrões morais e éticos, o trabalho decente se traduz no pleno desenvolvimento do trabalhador. Mas tal sempre dependerá, em grande parte, da cooperação internacional. Nesse lastro, é inarredável constatar que o desafio da implantação do trabalho decente, para a OIT, significa também atuar, em conjunto com outras instâncias nacionais e internacionais, na transposição das barreiras de que o alcance do desenvolvimento não prescinde.

Por fim, chama-se a atenção para o fato de que o direito ao desenvolvimento constitui o mais íntegro dos direitos fundamentais. Seu reconhecimento ultrapassa o domínio jurídico no sentido da ética social. Em sua clara universalidade e complexa indivisibilidade, encerra todos os demais, porque pressupõe a presença de dois requisitos essenciais: 1) que os direitos humanos e fundamentais sejam todos exercidos; 2) que sejam exercidos por todos. Assim, o desenvolvimento não admite exclusão: nem de direitos, nem de sujeitos.

\section{Referências}

Ahmed, Iftikhar, "Travail décent et développement humain", Revue Internationale du Travail, Genève, v. 142, n. 4 (2003), 287-295.

Bobbio, Norberto, A era dos direitos (Tradução: Carlos Nelson Coutinho), Rio de Janeiro, Elsevier, 2004. 
Bouvier-Ajam, Maurice, Histoire du travail en France depuis la Révolution, Paris, Librairie Générale de Droit et de Jusrisprudence, 1969, V. 2.

Cançado Trindade, A. A., A humanização do direito internacional, Belo Horizonte, Del Rey, 2006.

Cecato, M. A. Baroni, "Considerações acerca da dignidade do trabalhador em face da automatização", Verba Júris - Anuário da Pós-Graduação em Direito, João Pessoa, v. 4, n.4 (2005), 415-446.

Cecato, M. A. Baroni, "Direitos humanos do trabalhador: para além da Declaração de 1998 da OIT”, In: Rosa M. Godoy Silveira et alii, Educação em direitos humanos: fundamentos teórico-metodológicos, João Pessoa: Editora Universitária, 2007.

Delgado, Maurício Godinho, "Direito do trabalho e inclusão social: o desafio brasileiro", Revista LTR, São Paulo, a. 70, n. 10, out/2006, 1.159-1.169.

Diller, Janelle, "Responsabilité sociale et mondialisation: qu'attendre des codes de conduite, des labels sociaux et des pratiques d'investissement?", Revue Internationale du Travail, Genève, v. 138, n. 2 (1999), 107-139.

FIeldS, Gary S., "Travail décent et stratégies de développement", Revue Internationale du Travail, Genève, v. 142, n. 4 (2003), 261-286.

Huberman, Leo, História da riqueza do homem, Rio de Janeiro: Livros Técnicos e Científicos Editora SA, 2006.

Lamy, Pascal, Les droits économiques, sociaux et culturels dans le contexte des activités de développement des organisations internationales, disponível em: http://trade.ec.europa.eu/doclib/ docs/2004/october/tradoc_119412.pdf. Acesso em: 16 abr. 2008 .

Organisation des Nations Unies - ONU, Déclaration sur le droit au développement, New York, 1986, disponível em: http:// www.unhchr.ch/french/html/menu3/b/74_fr.htm. Acesso em: 21 jun. 2007.

Organisation des Nations Unies - ONU. Déclaration et Programme d'action de Vienne, New York, 1993, disponível em: 
http://www.unhchr. ch/huridocda/huridoca.nsf/(Symbol)/ A.CONF.157.23.Fr. Acesso em: 21 jun. 2007.

Organisation Internacionale du Travail - OIT, Déclaration relative aux principes et droits fondamentaux au travail et son suivi, Genève, 1998, disponível em: http://www.ilo.org/dyn/ declaris/DECLARATIONWEB.static_jump?var_Language $=$ FR\&var _pagename $=$ DECLARATIONTEXT. Acesso em: 24 jun. 2007.

Organisation des Nations Unies - ONU, Déclaration universelle des droits de l'homme, New York, 1948, disponível em: http:/ /www.un.org/ french/aboutun/dudh.htm. Acesso em 15 ago. 2007.

Organisation des Nations Unies - ONU, Pacte International relatif aux droits civils e politiques, New York, 1966, disponível em: http://www. diplomatie. gouv.fr /fr/actionsfrance_830/droits-homme_1048/droits-civilspolitiques_3025/pidcp_26507.html. Acesso em: 20 jun. 2007.

Organisation des Nations Unies - ONU, Pacte international relatif aux droits économiques, sociaux et culturels, New York, 1966, disponível em: http://www. unhchr. ch/french/ html/menu3/b/a_cescr_fr.htm. Acesso em: 20 jun. 2007.

Organisation des Nations Unies - ONU. Haut-commissariat des Nations Unies aux Droits de L'homme: La mondialisation et ses effets sur la pleine jouissance des droits de l'homme, disponível em: http://ap.ohchr.org/ documents/F/CHR/ resolutions/E-CN_4-RES-2005-17.doc. Acesso em 22 abr. 2008.

Organisation des Nations Unies - ONU, Communiqué de presse DH/G/1403 de La Sous-Commission Des Droits De L'homme, disponível em: http://www.un.org/News/fr-press/docs / 2001/DHG 1403.doc.htm. Acesso em: 22 abr. 2008.

Palmeira Sobrinho, Zéu, Terceirização e reestruturação produtiva, São Paulo, LTR, 2008.

Peces-Barba Martinez, Gregório, Lecciones de derechos fundamentales, Madrid, Dykisons, 2004. 
Sarlet, Ingo Wolfgang, A eficácia dos direitos fundamentais, Porto Alegre, Livraria do Advogado, 2001.

Sen, Amartya, "Travails et droits", Revue Internationale du Travail, Genebra: OIT, v. 139 (2000), 129-139.

SEn, Amartya, "Desenvolvimento como liberdade" (Tradução: Laura Teixeira Motta), São Paulo, Companhia das Letras, 2007.

Simm, Zeno, "Os direitos fundamentais nas relações de trabalho", Revista LTR, São Paulo, LTR, Ano 69, n. 11, nov./2005, 1.289-1.303.

Singer, Paul, "A cidadania para todos", In: Pinsk, Jaime; PINSK Carla B. (Orgs.) História da cidadania, São Paulo, Contexto, 2003,190-263.

Supiot, Alain, "Le travail en perspectives: Introduction", Revue Internationale du Travail. Genève, v. 135, n. 6 (1996), 663-674. Trindade, José Damião de Lima, "História social dos direitos humanos”, São Paulo, Peirópolis, 2002.

Maria Aurea Baroni Cecato

Professora do Programa de Pós-Graduação em Ciências Jurídicas Universidade Federal da Paraíba 